\title{
Injectable brain implant spies on individual neurons
}

\section{Electronic mesh has potential to unravel workings of mammalian brain.}

\section{BY ELIZABETH GIBNEY}

A simple injection is now all it takes to wire up a brain. A diverse team of physicists, neuroscientists and chemists has implanted mouse brains with a rolled-up, silky mesh studded with tiny electronic devices, and shown that it unfurls to spy on and stimulate individual neurons.

The implant has the potential to unravel the workings of the mammalian brain in unprecedented detail. "I think it's great, a very creative new approach to the problem of recording from large number of neurons in the brain," says Rafael Yuste, director of the Neurotechnology Center at Columbia University in New York, who was not involved in the work.

If eventually shown to be safe, the soft mesh might even be used in humans to treat conditions such as Parkinson's disease, says Charles Lieber, a chemist at Harvard University on Cambridge, Massachusetts, who led the team. The work was published in Nature Nanotechnology on 8 June ${ }^{1}$.

Neuroscientists still do not understand how the activities of individual brain cells translate to higher cognitive powers such as perception and emotion. The problem has spurred a hunt for technologies that will allow scientists to study thousands, or ideally millions, of neurons at once, but the use of brain implants is currently limited by several disadvantages. So far, even the best technologies have been composed of relatively rigid electronics that act like sandpaper on delicate neurons. They also struggle to track the same neuron over a long period, because individual cells move when an animal breathes or its heart beats.

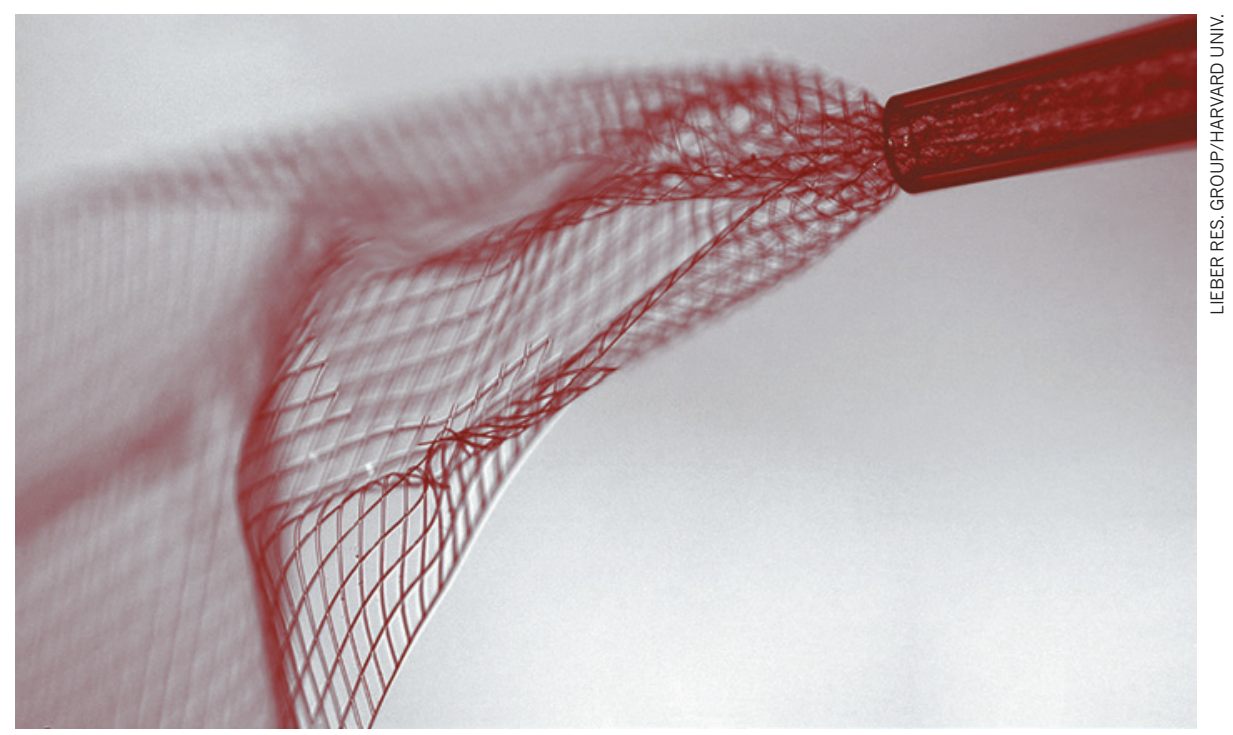

This soft, conductive polymer mesh can be rolled up and injected into the brains of mice.

The Harvard team solved these problems by using a mesh of conductive polymer threads with either nanoscale electrodes or transistors attached at their intersections. Each strand is as soft as silk and as flexible as brain tissue itself. Free space makes up 95\% of the mesh, allowing cells to arrange themselves around it.

In 2012 , the team showed ${ }^{2}$ that living cells grown in a dish can be coaxed to grow around these flexible scaffolds and meld with them, but this 'cyborg' tissue was created outside a living body. "The problem is, how do you get that into an existing brain?" says Lieber.

The team's answer was to tightly roll up a 2D mesh a few centimetres wide and then use a needle just 100 micrometres in diameter to

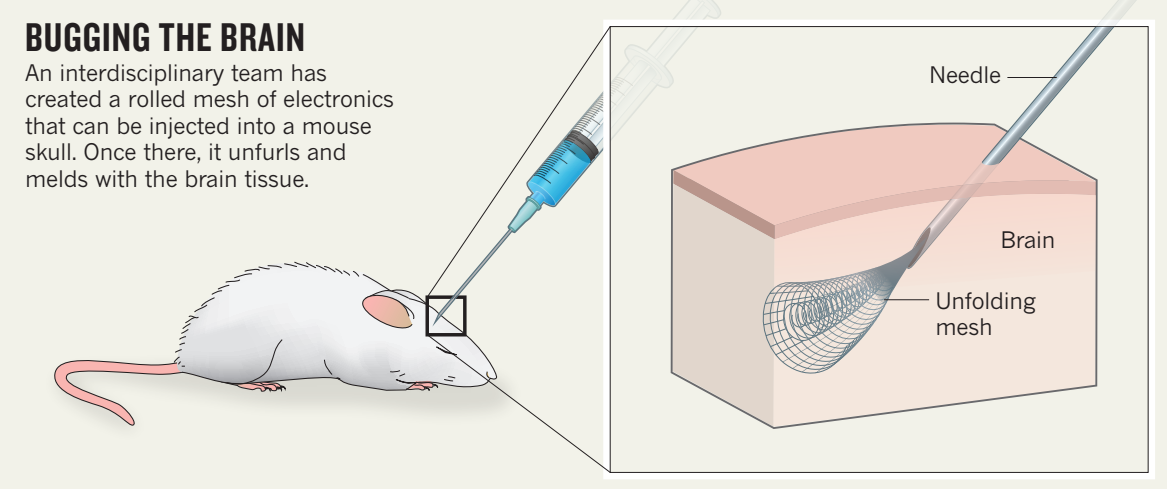

inject it directly into a target region through a hole in the top of the skull. The mesh unrolls to fill any small cavities and mingles with the tissue (see 'Bugging the brain'). Nanowires that poke out can be connected to a computer to take recordings and stimulate cells.

So far, the researchers have implanted meshes consisting of 16 electrical elements into two brain regions of anaesthetized mice, where they were able to both monitor and stimulate individual neurons. The mesh integrates tightly with the neural cells, says Jia Liu, a member of the Harvard team, with no signs of an elevated immune response after five weeks. Neurons "look at this polymer network as friendly, like a scaffold", he says.

The next steps will be to implant larger meshes containing hundreds of devices, with different kinds of sensors, and to record activity in mice that are awake, either by fixing their heads in place, or by developing wireless technologies that would record from neurons as the animals moved freely. The team would also like to inject the device into the brains of newborn mice, where it would unfold further as the brain grew, and to add hairpin-shaped nanowire probes to the mesh to record electrical activity inside and outside cells.

When Lieber presented the work at a conference in 2014, it "left a few of us with our jaws dropping", says Yuste. 
- There is huge potential for techniques that can study the activity of large numbers of neurons for a long period of time with only minimal damage, says Jens Schouenborg, head of the Neuronano Research Centre at Lund University in Sweden, who has developed a gelatin-based 'needle' for delivering electrodes to the brain ${ }^{3}$. But he remains sceptical of this technique: "I would like to see more evidence of the implant's longterm compatibility with the body," he says.
Rigorous testing would be needed before such a device could be implanted in people. But, says Lieber, it could potentially treat brain damage caused by a stroke, as well as Parkinson's disease.

Lieber's team is not funded by the US government's US\$4.5-billion Brain Research through Advancing Innovative Neurotechnologies (BRAIN) initiative, launched in 2013, but the work points to the power of that effort's multidisciplinary approach, says Yuste, who was an early proponent of the BRAIN initiative. Bringing physical scientists into neuroscience, he says, could help to "break through the major experimental and theoretical challenges that we have to conquer in order to understand how the brain works". -

1. Liu, J. et al. Nature Nanotechnol. http://dx.doi. org/10.1038/nnano.2015.115 (2015).

2. Tian, B. et al. Nature Mater. 11, 986-994 (2012).

3. Lind, G., Linsmeier, C. E., Thelin, J. \& Schouenborg, J. J. Neural Eng. 7, 046005 (2010).

\section{Start-ups fight for a place in Boston's biotech hub}

\section{Competition for lab space threatens Kendall Square's innovative spark.}

\section{BY HEIDI LEDFORD}

A $s$ venture capitalist Kevin Bitterman gets ready to launch his latest start-up, he knows exactly where he wants it to be: Kendall Square, a densely populated neighbourhood in Cambridge and the heart of Boston's booming biotechnology industry. "You can't walk two feet there without seeing someone in biotech," he says. "That kinetic energy of having everybody squished together - it leads to a lot of advantages you can't get outside the city."

But Bitterman, a partner at the firm Polaris Partners in Boston, Massachusetts, finds himself contemplating the unthinkable: exile to the suburbs. Space in Kendall Square has always been tight, but now it is nearly impossible to find - particularly for young start-ups, he says. Two years ago, when he sought a home for another fledgling firm, Bitterman says he could count the options in the area on one hand. "But at least we had one hand of options to look at," he says. "There's literally nothing now."

The Boston-area biotech community is among the largest and densest in the world, with Kendall Square at its epicentre. The neighbourhood squeezes 120 biomedical firms within a 1.5 -kilometre radius. The density and diversity of the biotech ecosystem make Kendall unique, says Fiona Murray, associate dean for innovation at the nearby Massachusetts Institute of Technology (MIT) Sloan School of Management. The area is home to biomedical firms large and small, but also to the investors, patent lawyers, contract research organizations and suppliers they need to support them. "There's an extraordinary supply of human talent," says Murray.

But some say that the region may become

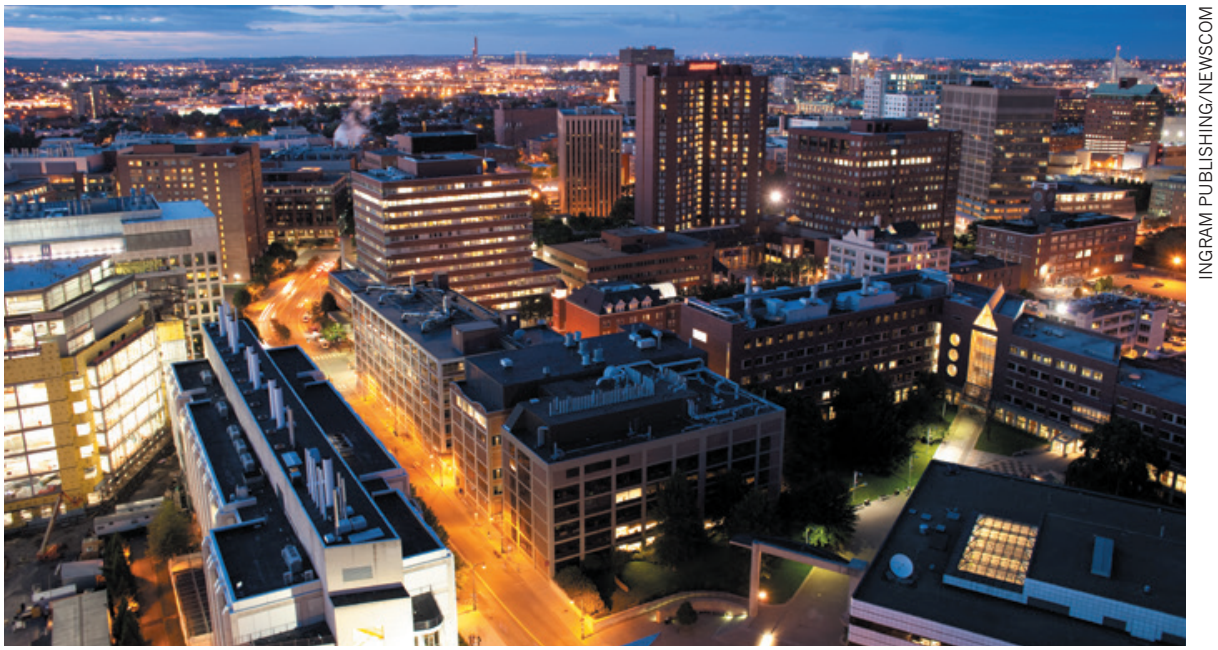

Technology and drug firms dominate the Kendall Square neighbourhood of Cambridge, Massachusetts.

a victim of its own success. Since the 1970s, Kendall Square has evolved from an industrial centre dotted with brick factory buildings into a hub of high-tech and biotech firms such as Biogen and Genzyme. Over the past five years, the technology giants Google and Microsoft and the multinational drug firms Novartis and Pfizer have dramatically expanded their offices and laboratories in the neighbourhood, eager to build close relationships with hot start-ups and the academic powerhouses of Harvard University and MIT. The influx threatens to squeeze out the start-up companies that have helped to make Kendall Square what it is. "There are so many benefits of being right here," says Chuck Wilson, who started the cancer-focused firm Unum Therapeutics in Kendall Square last year. The firm is growing so quickly that it will almost certainly need to leave the neighbourhood within months to get enough space.

At the same time, more-mature homegrown companies such as Alnylam Pharmaceuticals, which develops RNA-based therapies, and cancer-drug developer ARIAD Pharmaceuticals are expanding. "Companies that were only founded a couple of years ago are now gobbling up a lot of space," says Eric Smith, a partner in the Boston office of the commercial-property firm Transwestern.

Young biotechs also compete with high-tech firms so desperate for office space in Cambridge that they are renting buildings designed to accommodate labs. Since the end of 2012, lab rents in the Kendall Square area have risen by $13 \%$ to an annual rate of just over US $\$ 770$ per square metre (see 'Up and away'). Over the same period, annual office rents rose by $26 \%$ to just over $\$ 700$ per square metre. 